
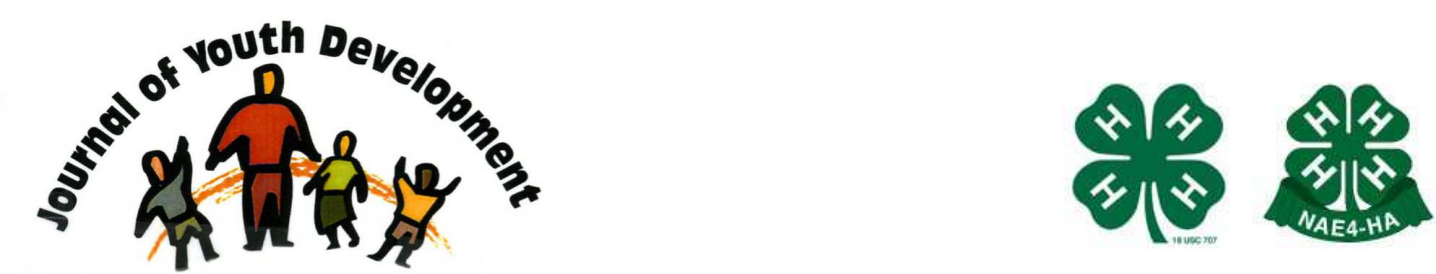

Bridging Research \& Practice

\title{
"Catch 'Em Being Good:" An Extension Service and State School System Team Up to Promote Positive Outcomes for Youth
}

\author{
Kerri Wade \\ West Virginia University Extension Service \\ Dunbar, WV \\ kerri.wade@mail.wvu.edu
}

Allison Nichols

West Virginia University Extension Service

Morgantown, WV

ahnichols@mail.wvu.edu 


\title{
JOURNAL OF YOUTH DEVELOPMENT \\ bridging research and practice

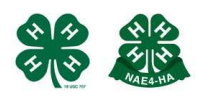

Volume 3, Number 3, Winter 2008

Article 080303PA001

\section{"Catch 'Em Being Good:" \\ An Extension Service and State School System Team Up to Promote Positive Outcomes for Youth}

\author{
Kerri Wade and Allison Nichols \\ West Virginia University Extension Service
}

\begin{abstract}
This feature article describes a collaboration between the West Virginia University Extension Service and the West Virginia Department of Education to implement the "Responsible Students through School Wide Positive Behavior Supports" program (RS-SWPBS) throughout the state. A case study of Grandview Elementary School in Kanawha County illustrates the benefits that the collaboration brought to local youth. West Virginia Department of Education established the program and brought local schools onboard, while educators from the West Virginia University Extension Service became coaches and led the effort to collect and analyze data. Results included the development of positive behaviors, a decrease in negative behaviors, and the creation of a positive school climate.
\end{abstract}

\section{Introduction}

Creating a positive learning environment for youth in today's schools is challenging for educators. Many find that they must accommodate students with significant learning and behavioral problems and work under conditions that are counterproductive to learning (Lewis, \& Sugai, 1999). Schools in West Virginia have been searching for ways to improve school climate, student behavior, and student achievement to meet the requirements of the No Child Left Behind Act (NCLB, 2001). In 1993, the West Virginia Legislature passed state code requiring all schools to develop a preventative discipline program. Today, because of a partnership between the West Virginia University Extension Service (WVUES) and the West Virginia Board of Education (WVDE), a program called Responsible Students through School Wide Positive Behavior Supports (RS-SWPBS) has been established statewide. Its mission is to provide safe learning environments for children and youth focused on academic and behavioral achievement. 
In 2001, the WVUES received a school violence prevention grant from the U.S. Department of Education. A team of WVU Extension educators determined that RS-SWPBS addressed the goals set forth in the grant application. In July 2001, WVUES and WVDE reached a collaborative agreement to help school districts adopt RS-SWPBS. WVDE provided training and WVUES coached school leadership teams as well as provided technical support in the form of research tools and databases. The authors of this article describe this collaborative effort by telling the story of Grandview Elementary in Charleston, West Virginia.

\section{The School Wide Positive Behavior Support Model}

Many schools respond to behavior problems by establishing "zero tolerance" policies, however, punishment without a school-wide system of positive support increases levels of aggression, vandalism, truancy and dropout (Covington, 2000; Merret, \& Thorpe, 1996; Mitchem, Young, \& West, 2000; Stewart, \& Evans, 1997; Sulzer-Azarof, \& Mayer, 1991). Substantial research indicates that if teachers want to influence learning and behavior and improve student achievement, they must reinforce and reward positive behavior (Hardman, \& Smith, 1999; Kaplan, Hemmes, Motz, \& Rodriquez, 1996; Mitchem, Young, \& West, 2000). Schools that implement SWPBS tend to see lower levels of student problem behavior and improved academic performance (Blum, McNeely, \& Rinehart, 2002). If school rules are fairly applied and the consequences for not obeying them are known, fewer youth will become victims of violence and mistreatment by other students (Mayer, 1995).

The SWPBS program is comprised of a broad range of large group and individualized strategies. SWPBS is not a specific practice or curriculum; it is an approach to prevention/early intervention, based upon the scientific principles of applied behavior analysis (Sugai, \& Homer, 2002). According to the SWPBS continuum, a triangular model demonstrates student behavior. The top point of the triangle constitutes high-risk students or $5 \%$ of the student population who require tertiary prevention, including specialized and individualized plans. The second layer of the triangle constitutes $15 \%$ of the school population: students requiring secondary prevention. Three-fourths (75-80\%) of the student population comprises the bottom portion of the triangle, those who only require primary prevention, and the SWPBS process focuses on this group. Once the primary prevention is in place, the staff can address the individualized needs of the remaining students.

The SWPBS process includes the following ten steps:

1) Develop a leadership team.

2) Recruit supporters.

3) Assess problems.

4) Establish three to five behavioral expectations for the school.

5) Develop an acknowledgement system.

6) Teach the behavioral expectations and the acknowledgement system.

7) Establish a Teach-Re-Teach System and acknowledgement system.

8) Continue ongoing decision making based on data.

9) Develop a procedure to identify and assist students with chronic problem behavior.

10) Continue a public relations effort. 


\section{West Virginia University Extension Service's Involvement in RS-SWPBS}

\section{Role One: Coach}

In 001, the WVDE provided training on how to implement RS-SWPBS for the first group of 45 school-based leadership teams. Over 200 teachers, administrators, university professors, Extension agents and state department staff learned how to develop and implement West Virginia's model. WVUES provided coaches for most teams. One of those teams was from the Grandview Elementary School in Kanawha County. The team included the principal, the counselor, and three lead teachers. Grandview Elementary is an urban school. At Grandview Elementary, the student minority population averages $17 \%$, well above the state's average of $4 \%$. Almost two-thirds of the 270 pre-kindergarten to fifth-grade students qualify for the free and reduced lunch program (62\%).

At the end of the initial training, Grandview Elementary team members lacked confidence in implementing the RS-SWPBS process. Because there was no standard curriculum several members commented, "Where is the manual?" and, "They didn't tell us how to do this!" As coach, the Extension Agent helped team members gain confidence in their ability to implement the program. She attended monthly staff /professional development meetings and presented the RS-SWPBS model to the entire school staff. She conducted a school assessment survey and collected baseline referral data. As she guided the staff in their understanding of the results of the assessment survey and baseline referral data, they understood for the first time the level of discipline problems in their school. This was a turning point in the school's history.

The school staff began drafting school-wide expectations. Since the school's mascot is an eagle, they built upon an eagle theme and selected the following expectations:

1) expect to do your best,

2) accept responsibility,

3) give and earn respect, and

4) listen and learn.

In January of 2002, Grandview Elementary, with the assistance of the Extension agent, conducted a kick-off event to introduce RS-SWPBS to the students, parents and community.

\section{Role Two: Data Collector and Analyzer}

The Extension agent worked with the school staff to compile baseline data including academics, attendance, promotion/ retention rates, disciplinary office referrals, primary behaviors, disciplinary actions by location, grade level, gender, and ethnicity. She collected data in 2001 and again in 2003 and compared the two data sets.

\section{Other Resources Provided by Extension}

WVUES professionals provided other resources to support the RS-SWPBS process. The Extension Evaluation Specialist developed the core team questionnaire and analyzed the results. Extension Service faculty made presentations at workshops and conferences and reported on the West Virginia RS-SWPBS effort through a technical report to the U.S. Department of Education and to U. S. Senator Robert C. Byrd. The Kanawha County Extension Agent was able to leverage the resources of the county office to provide on-going programs including nutrition 
classes for students and workshops for families, a 4-H after-school program and Family "Fun Nights."

\section{Results}

The collaboration between West Virginia University Extension and the West Virginia Board of Education benefited both the students at Grandview Elementary as well as the state school system.

\section{Benefits to the students at Grandview Elementary}

1. Fewer students were referred to the principal's office for disciplinary reasons.

Baseline data, collected in the 2000/01 school year, showed that there were 250 discipline referrals to the office. Over the four years of implementation, disciplinary referrals steadily decreased to 105 referrals. This is an overall decrease of $58 \%$. Based on 180 school days per year, the average number of referrals per day dropped from 1.38 to 0.583 .

\section{Table 1}

Total Office Referrals

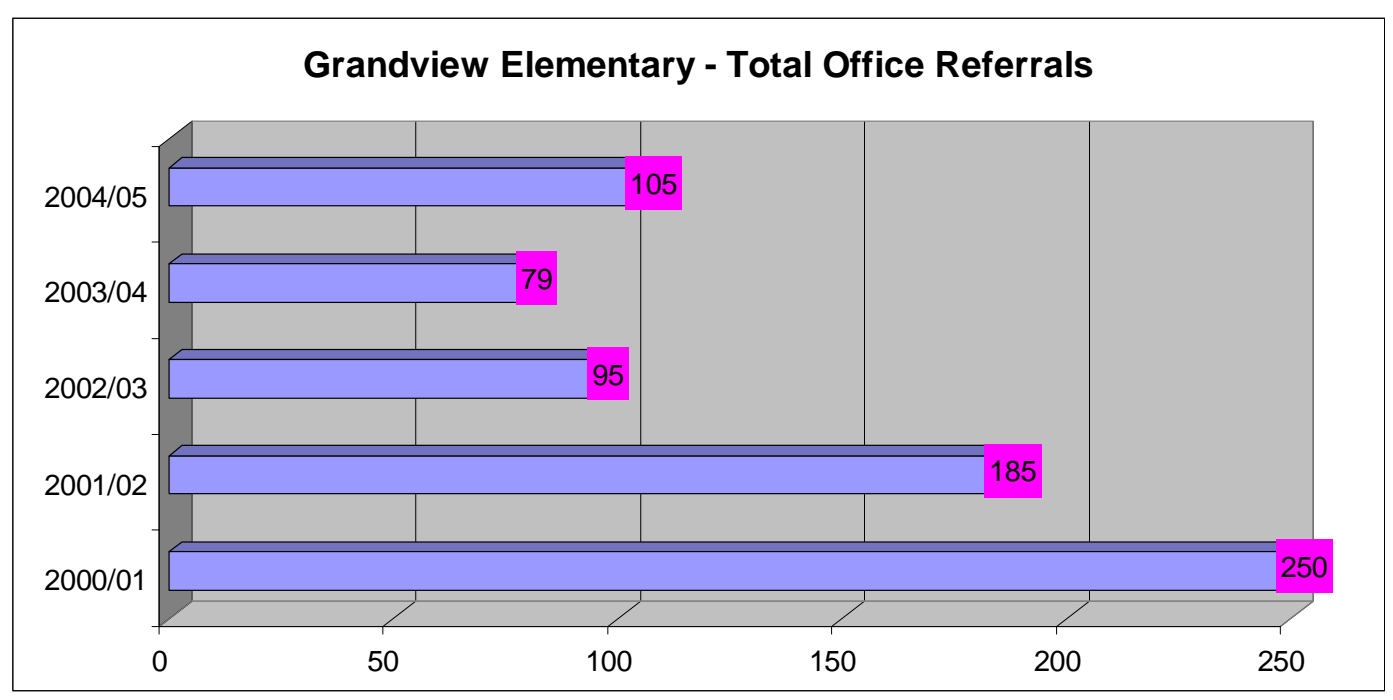

2. The number of primary behavior incidents decreased dramatically.

In 2000/01, there were 107 reported incidents of fighting, but in 2004/05, there were only 17. This is an improvement of $82.2 \%(n=90)$. 
Table 2

Primary Behavior Incidents

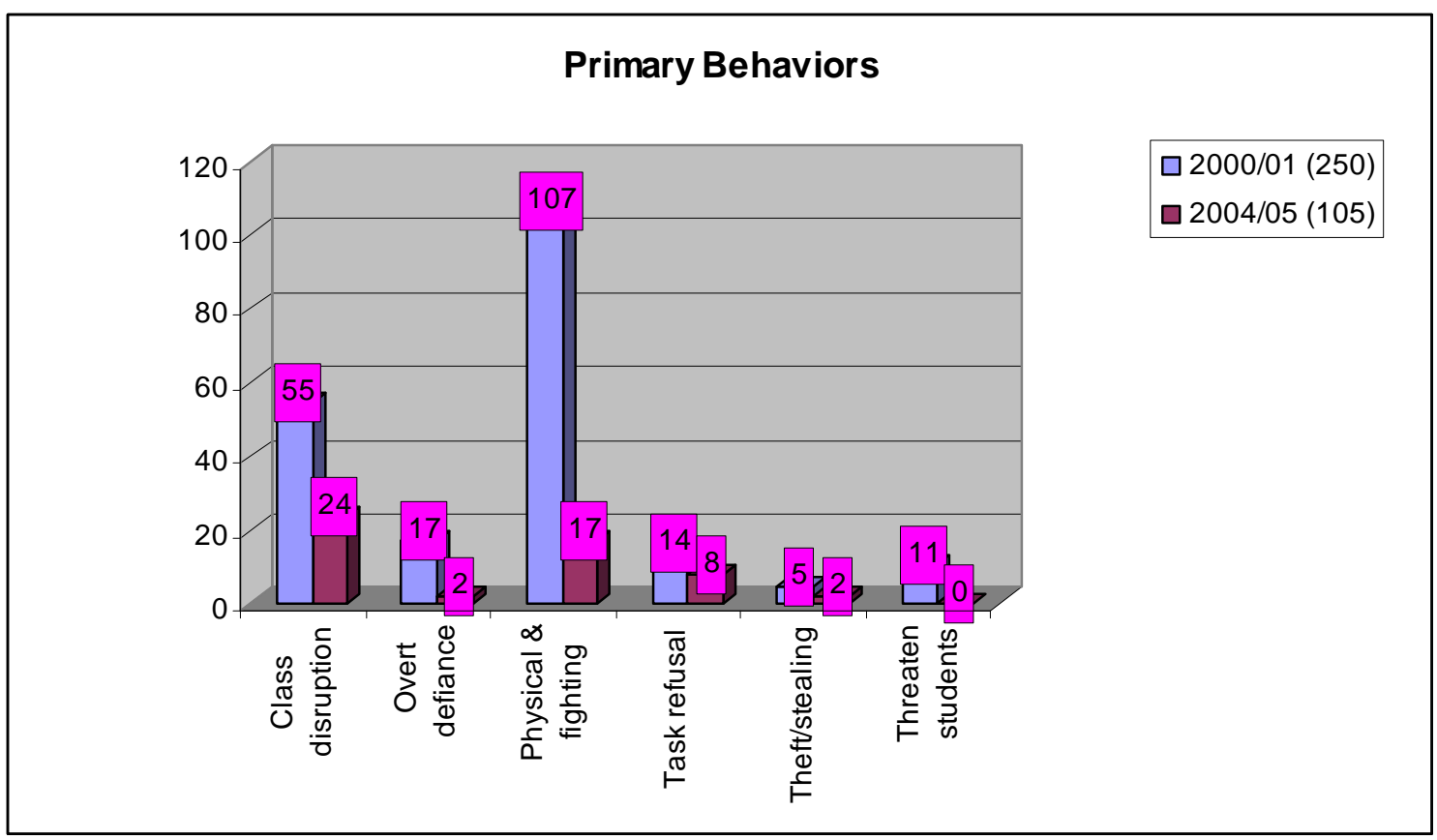

3. Students enjoy safer and more learner-friendly classrooms.

Incidents in the classroom went from 130 in 2000/01 to 49 in 2004/05. This is a $62.4 \%$ decrease. Another category of dramatic improvement was the classroom disruptions. In 2000/01, there 55 reported disruptions. This number decreased by $56.4 \%$.

Table 3

Primary Location of Behavior Incidents

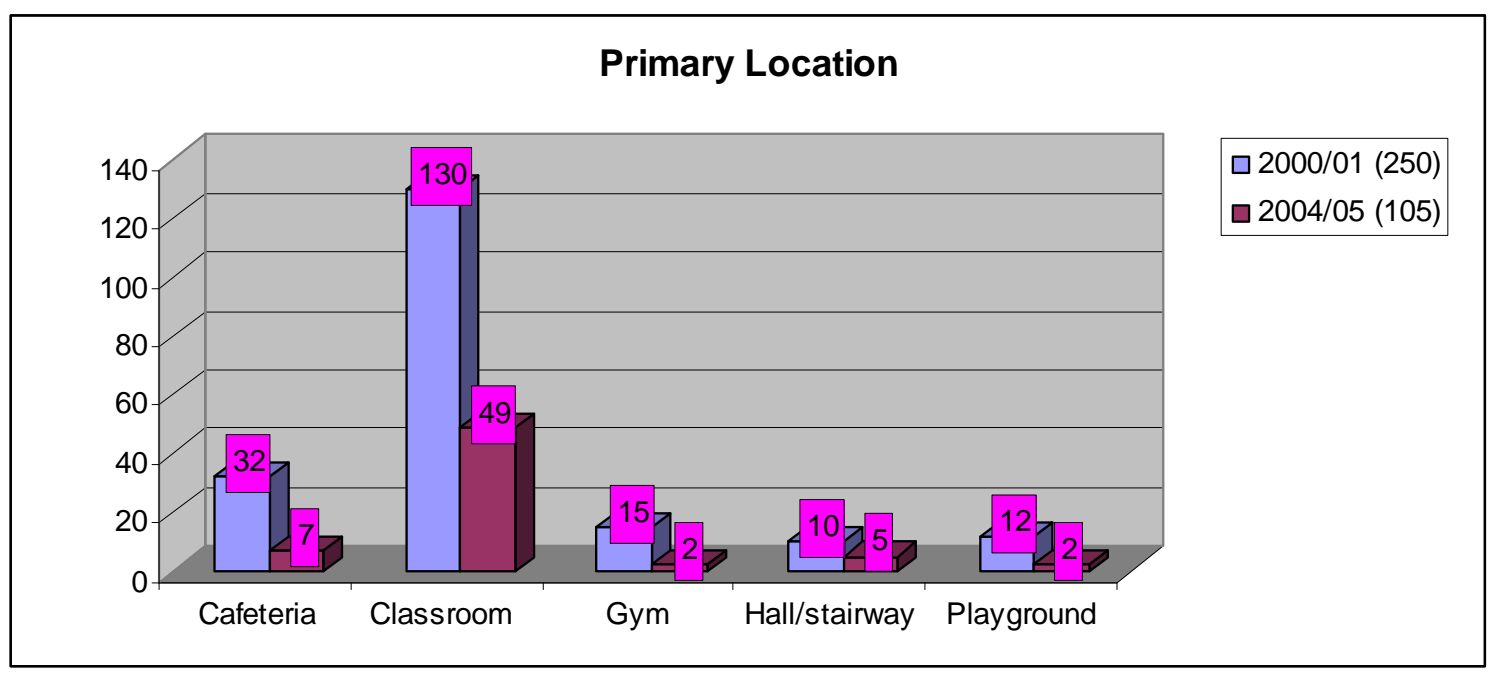


4. Most primary behavior incidents are now handled at the classroom level; administrators handle only the serious cases.

During the year of baseline data collection, teachers referred 87 children to the office without first trying to address the primary behavior problem. This number decreased to five in 2004/05 $(94.3 \%)$. Now, if a teacher refers a child to the office, he or she has already taken appropriate action for primary behavior management and the next level of intervention can begin.

5. Minority students are no longer viewed as a "problem-behavior group." Ethnicity by incident more accurately reflects the school population.

In 2000, African American students were responsible for $46 \%(n=79)$ of the reported incidents even though African American children represented only $17 \%$ of the total school population. In 2005 , that number was reduced to $24.7 \%(n=26)$.

Table 4

Disciplinary Action by Ethnicity

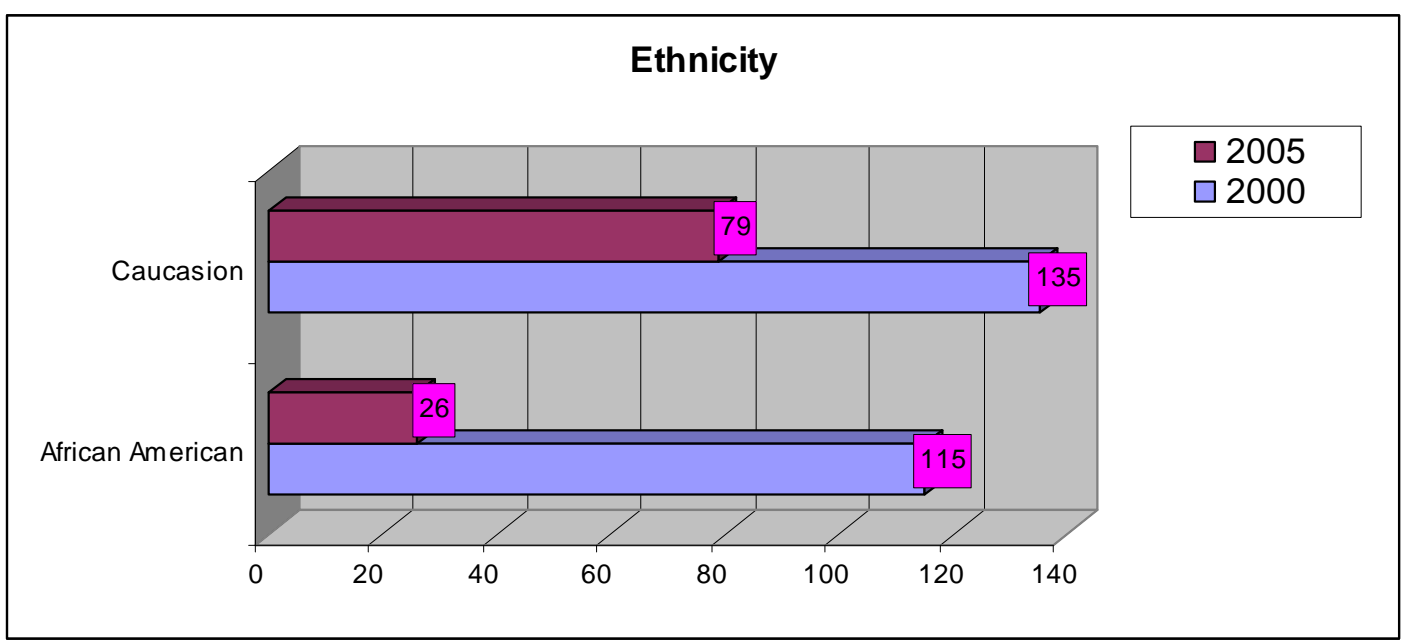

6. The number of children requiring tertiary intervention has decreased, and those that do, are receiving appropriate services.

At Grandview Elementary, students with more than five discipline referrals require tertiary prevention. In $2000 / 01,11$ students fit this criterion. This is $3.95 \%$ of the student population. In $2004 / 05$, four students needed tertiary interventions. This is $1.73 \%$ of the student population, an improvement of $63.7 \%$.

The number of referrals also decreased. In 2000, the three students with the most referrals received 22, 21, and 14 referrals, respectfully. In 2005, the three students with the most referrals received 11,10 and 5 referrals, respectfully. This change is statistically significant. 
Table 5

Primary Discipline Actions

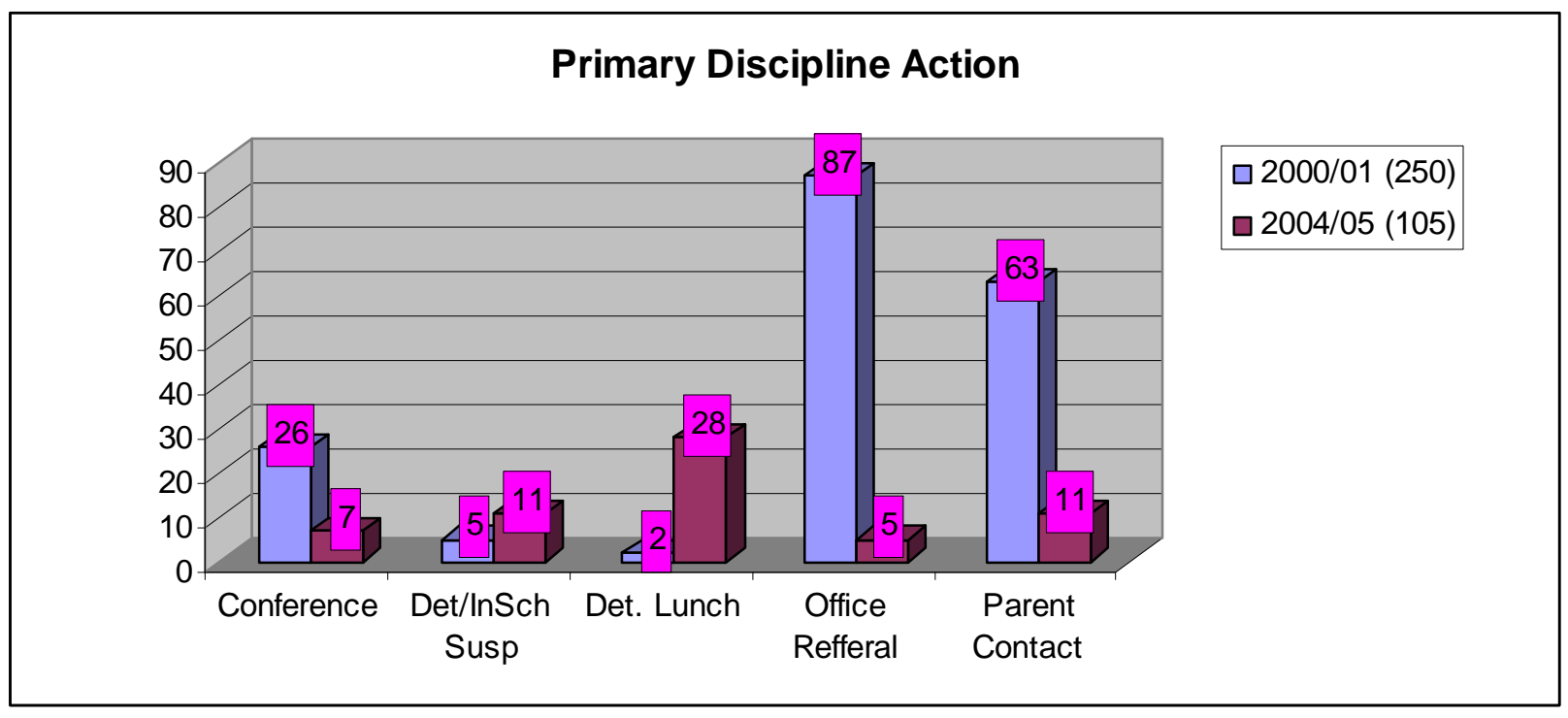

\section{Benefits to the state school system}

1. The RS-SPBS training model, which included a coach for each school team, expanded statewide.

As it became apparent that the role of the local coach was important to the success of SWPBS, the WVDE formalized the requirement for a coach and created a coach's manual.

Superintendents are now required to select the local coach before a school can enroll in an RSSWPBS training seminar and put the commitment in writing. The local coach is required to attend a coaches' training session, the school-team training session, and all follow-up sessions. The local coach position has improved the integrity of the RS-SWPBS process in West Virginia.

2. The database created by the Extension agent coach was offered to all schools in WV.

WV RS-SWPBS teams were not comfortable using the internal data collection/reporting system, "West Virginia Educational Information System" (WVEIS) because if they reported all offenses, not just tertiary offenses, their school would be labeled as a dangerous school. (The WV Board of Education requires schools to report only high-level offenses such as drug use, weapon possession, and suspensions.) The RS-SWPBS database, underwent three revisions, and was finally offered as an alternative to the WVEIS system.

\section{Conclusion and Recommendations}

The collaboration between West Virginia University Extension and the West Virginia Board of Education to implement RS-SWPBS throughout West Virginia resulted in positive outcomes for children and youth in West Virginia, including the development of positive behaviors, a decrease 
in negative behaviors, and the creation of a positive school climate. The authors recommend that readers, both in Extension and in community institutions and organizations seek out similar collaborative arrangements.

Recommendations for developing programs that result in positive outcomes for youth include:

1) Develop a program plan designed to meet specific youth outcomes using a logic model approach to program development. The University of Wisconsin Extension website offers many tips for using logic models for program development. Visit: http://www.uwex.edu/ces/pdande/evaluation/evallogicmodel.html.

2) Determine your organization's strengths and weaknesses with regard to meeting specified outcomes. Determine where collaboration is appropriate.

3) Get to know the resources of organizations in your state and community related to positive youth development. Every state has a land grant institution of higher education with Extension Service. To locate a listing of all Land Grant Institutions visit: http://www.higher-ed.org/resources/land grant colleges.htm.

4) Strengthen your plan by collaborating with other organizations, allowing each to bring their expertise to the program.

5) Develop indicators for success and collect baseline data.

6) Compare changes in baseline data over time.

7) Allow each organization to share in the analysis of the data.

8) Allow each organization to take credit for successes and share the results with their stakeholders.

\section{References}

Blum, R.W., McNeely, C.A., \& Rinehart, P.M. (2002). Improving the Odds: The Untapped Power of Schools to Improve the Health of Teens. Minneapolis, MN: Center for Adolescent Health and Development, University of Minnesota.

Covington, M.V. (2000). "Goal Theory, Motivation, and School Achievement: An Integrative Review." Annual Review of Psychology 51: 171-200.

Hardman, E., \& Smith, S.W. (1999). "Effective Behavior Support: A Systems Approach to Proactive School Wide Management." Focus on Exceptional Children 31(6): 1-24.

Lewis, T., Sugai, G. (1999). "Effective Behavior Support: A Systems Approach to Proactive School wide Management." Focus on Exceptional Children 31(6): 1-24.

Kaplan, H., Hemmes, N.S., Motz, P., \& Rodriquez, H. (1996). "Self-reinforcement and Persons with Developmental Disabilities." The Psychological Record 46(1): 161-179.

Mayer, G.R. (1995). "Preventing Antisocial Behavior in the Schools." Journal of Applied Behavior Analysis 28(4): 467-478. 
Merrett, F., \& Thorpe, S. (1996). "How Important Is the Praise Element in the Pause, Prompt and Praise Tutoring Procedures for Older Low-progress Readers?" Educational Psychology 16(2): 193-206.

Mitchem, K.J., Young, R. \& West, R.P. (2000). "Changing Student, Parent, and Faculty Perceptions: School is a Positive Place." Intervention in School and Clinic 35(4): 248-252.

Stewart, S.C., \& Evans. W.H. (1997). "Setting the Stage for Success: Assessing the Instructional Environment." Preventing School Failure 41(2): 53-56.

Sugai, G., Homer, R.H. (2002). "The Evolution of Discipline Practices: School-wide Positive Behavior Supports." Child and Family Behavior Therapy 24: 23-50.

Sulzer-Azaroff, B. \& Mayer, G.R. (1991). Behavior Analysis for Lasting Change. Fort Worth: Holt, Rinehart.

U.S. Department of Education. (2001). "No Child Left Behind Act" (Overview Fact Sheet). Washington: ed.gov. Retrieved October 2006 from http://www.ed.gov/nclb/overview/intro/factsheet.html

(C) Copyright of Journal of Youth Development Bridging Research and Practice. Content may not be copied or emailed to multiple sites or posted to a listserv without copyright holder's express written permission. Contact Editor at: patricia.dawson@oregonstate.edu for details. However, users may print, download or email articles for individual use.

ISSN 2325-4009 (Print); ISSN 2325-4017 (Online) 